\title{
中国北方温带灌丛生物量的分布及其与环境的关系
}

\author{
杨 弦 ${ }^{1}$ 郭炎培 ${ }^{1}$ 安尼瓦尔. 买买提 ${ }^{2}$ 刘鸿赝 $^{1}$ 马文红 ${ }^{3}$ 于顺利 ${ }^{4}$ 唐志尧 $1^{*}$ \\ ${ }^{1}$ 北京大学城市与环境学院, 北京 $100871 ;{ }^{2}$ 中国科学院新疆生态与地理研究所, 乌鲁木齐 $830011 ;{ }^{3}$ 内蒙古大学生命科学学院, 呼和浩特 $010021 ;{ }^{4}$ 中 \\ 国科学院植物研究所植被与环境变化国家重点实验室, 北京 100093
}

摘 要 目前对植物生物量分布格局和分配的研究多集中在森林和草地生态系统, 对灌从的相关研究较少。灌从是中国北方 广泛分布的植被。研究灌从生物量分布格局及其分配是对估算我国陆地生态系统碳库的重要补充。该文通过对中国北方温带 灌从的大范围野外调查和采样, 计算中国北方 433 个典型灌从样地的生物量及其在各器官间的分配, 并研究它们与气候和土 壤营养等环境因子的关系。结果表明: 中国北方温带灌从平均生物量为 $12.5 \mathrm{t} \cdot \mathrm{hm}^{-2}$, 其中灌木层地上、地下生物量分别为 4.5 和5.4 t $\cdot \mathrm{hm}^{-2}$, 草本层地上、地下生物量分别为 0.8 和 $1.8 \mathrm{t} \cdot \mathrm{hm}^{-2}$; 调落物量为 $2.5 \mathrm{t} \cdot \mathrm{hm}^{-2}$ 。不同类型中, 温带落叶灌从、亚高山落 叶阔叶灌从、荒漠灌从平均生物量分别为 $14.4 、 28.8$ 和 $5.0 \mathrm{t} \cdot \mathrm{hm}^{-2}$ 。东西部生物量分布差异较大, 东部温带落叶灌从总生物量 高于西部的荒漠灌从。东部温带落叶灌从中, 东北地区的灌从生物量稍低于华北地区。灌木的地下-地上生物量比不随水分 和土壤养分变化, 而叶-枝生物量比受水分影响, 在干旱区域叶-枝生物量比较低。

关键词＼cjkstart灌丛; 生物量密度; 地下-地上生物量比; 叶-枝生物量比

引用格式: 杨弦, 郭炎培, 安尼瓦尔. 买买提, 刘鸿雁, 马文红, 于顺利, 唐志尧 (2017). 中国北方温带灌从生物量的分布及其与环境的关系. 植物生态 学报, 41, 22-30. doi: 10.17521/cjpe.2016.0199

\section{Distribution of biomass in relation to environments in shrublands of temperate China}

YANG Xian ${ }^{1}$, GUO Yan-Pei ${ }^{1}$, MOHHAMOT Anwar ${ }^{2}$, LIU Hong-Yan ${ }^{1}$, MA Wen-Hong ${ }^{3}$, YU Shun-Li ${ }^{4}$, and TANG Zhi-Yao ${ }^{1^{*}}$

${ }^{1}$ College of Urban and Environmental Science, Peking University, Beijing 100871, China; ${ }^{2}$ Xinjiang Institute of Ecology and Geography, Chinese Academy of Sciences, Ürümqi 830011, China; ${ }^{3}$ College of Life Sciences, Inner Mongolia University, Hohhot 010021, China; and ${ }^{4}$ State Key Laboratory of Vegetation and Environmental Change, Institute of Botany, Chinese Academy of Sciences, Beijing 100093, China

\section{Abstract}

Aims Shrubland is one of the most widely distributed vegetation types in northern China. Previous studies on pattern and dynamics of plant biomass have been focused on forest and grassland ecosystems, while relevant knowledge on shrubland ecosystems is lacking. It is important to include shrublands in northern China to improve the accuracy in estimating the terrestrial ecosystem biomass in China.

Methods Based on investigations and samplings from 433 shrubland sites, we explored the distribution and allocation patterns of biomass in relation to climatic and soil nutrient factors of shrublands of temperate China.

Important findings The average shrubland biomass density in northern China is $12.5 \mathrm{t} \cdot \mathrm{hm}^{-2}$. It decreases significantly from temperate deciduous shrubland in northeast to desert shrubland in northwest. The average biomass density of temperate deciduous shrubland, alpine shrubland, and desert shrubland is 14.4, 28.8, and 5.0 $\mathrm{t} \cdot \mathrm{hm}^{-2}$, respectively. Within temperate deciduous shrublands, plant biomass is lower in North China than in Northeast China. The average aboveground and belowground biomass density of shrub layer is $4.5 \mathrm{and} 5.4 \mathrm{t} \cdot \mathrm{hm}{ }^{-2}$, respectively; while that of grass layer is 0.8 and $1.8 \mathrm{t} \cdot \mathrm{hm}^{-2}$, respectively. Environmental factors affect biomass allocation across different plant organs. The belowground-aboveground biomass ratio of shrub exhibits no significant changes with environmental variables. The leaf-stem ratio increases with annual precipitation, and leaf biomass is low in arid region.

Key words shrubland biome; biomass density; belowground-aboveground biomass ratio; leaf-stem biomass ratio

Citation: Yang X, Guo YP, Mohhamot A, Liu HY, Ma WH, Yu SL, Tang ZY (2017). Distribution of biomass in relation to environments in shrublands of temperate China. Chinese Journal of Plant Ecology, 41, 22-30. doi: 10.17521/cjpe.2016.0199

收稿日期Received: 2016-06-13 接受日期Accepted: 2016-07-23

* 通信作者Author for correspondence (E-mail: zytang@urban.pku.edu.cn) 
灌从生态系统是我国重要的植被碳库(胡会峰 等, 2006)。研究灌丛的生物量分布格局和分配是对 我国估算整个陆地生态系统生物量的重要补充。然 而, 由于研究数据的缺乏, 开展大尺度的灌丛生物 量研究面临着巨大的困难。相对于森林和草地的生 物量研究来说, 对我国灌从的相应研究较少。国内 对灌从生物量的研究开始于 20 世纪 80 年代(姜凤岐 和卢风勇, 1982), 后来的一系列研究估算了不同类 型灌从的生物量密度(贺金生等, 1997; 罗天祥等, 1999; 陈遐林等, 2002; 刘国华等, 2003a, 2003b)。现 有的灌从生物量研究往往着眼于特定地区或特定类 型的灌从, 难以从区域尺度上反映灌丛生物量的分 布格局。

植物为了适应不同的环境条件, 可能将资源分 配到不同的器官, 植物各器官的生物量比值, 如地 下-地上生物量比或根冠比反映了植物生物量在不 同器官中的分配策略。根据植物生长的类经济学模 型及平衡生长假说, 植物将资源分配到各个器官以 使得生物量生产最大化, 当某一资源最为限制植物 生长时, 植物将倾向于把更多生物量分配给获取该 资源的器官(Bloom et al., 1985; Chapin et al., 1987)。 例如在干旱或养分贫㾑的土壤中, 植物会增加根系 的生长来加强对水和氮磷的吸收, 从而导致更高的 地下-地上生物量比(Subbarao et al., 1995; Turner \& Haygarth, 2001)。随着植物密度的增加, 植物对光的 竞争增强会使得叶生物量减少而茎生物量增加, 即 叶-枝比减小, 这可能是因为茎的生长可以使得叶 处于群落上层, 从而获得更多的光(Poorter et al., 2012)。Markesteijn和Poorter (2009)发现, 降水对热 带森林生态系统地下-地上生物量比具有重要的影 响, 一般而言, 干旱地区的森林具有较大的地下生 物量, 而湿润地区的森林地下生物量较小, 因此其 地下-地上生物量比随着降水增加而减小。王娓等 (2008)认为中国北方草地地下-地上生物量比随温度 变化不明显, 随降水增加而降低; 但Yang等(2010) 认为中国草地的地下-地上生物量比与温度降水都 没有显著关系。与之相比, 对灌从生物量分配的研 究依旧主要关注特定地区和特定类型的灌从(王勇 军等, 2010; 雷蕾等, 2011; 高巧等, 2014; 钟泽兵 等, 2014), 缺乏大尺度研究。

灌从广泛分布于我国北方地区, 占据了大量森 林和草地无法发育的生境。研究北方灌从的生物量
分布格局和分配策略能够加深对环境胁迫下的植物 群落状况的认识。中国北方灌从中的灌木植物基本 为落叶灌木, 将其作为研究对象能排除常绿和落叶 生活型差异造成的误差; 另一方面, 干旱是中国北 方植物生长的主要限制因子(Bai et al., 2008), 将中 国北方作为研究区域有助于深入理解水分对灌从植 被生物量极其分配策略的影响。因此, 我们以中国 北方所有的灌从作为研究对象, 估算了灌从生物量 在中国北方的分布格局以及气候和土壤因子对灌从 生物量分配的影响。

\section{1 材料和方法}

\section{1 调查和采样}

研究区域包括了中国北方 14 个省级行政区, 即 北京、天津、河北、山西、内蒙古、辽宁、吉林、 黑龙江、山东、河南、陕西、甘肃、宁夏、新疆。 在研究区域内, 我们共调查了 433 个典型灌丛样地, 包括321个落叶阔叶灌从样地、4个亚高山灌从样地 及 108 个荒漠灌从样地(图1)。样地跨越了 $19.8^{\circ}$ 纬度 $\left(32.6^{\circ}-52.4^{\circ} \mathrm{N}\right)$ 和 $57.2^{\circ}$ 经度 $\left(75.6^{\circ}-132.8^{\circ} \mathrm{E}\right)$, 年平 均气温范围为-2.7-15.2 ${ }^{\circ} \mathrm{C}$, 年降水量为 8.1$1049.9 \mathrm{~mm}$ 。

每个样地设置了 3 个 $5 \mathrm{~m} \times 5 \mathrm{~m}$ 的重复样方, 记 录样方的各环境因子(包括经纬度、海拔、坡度、坡 向等)和群落概况(包括群落类型、优势种、盖度等)。 为准确测量样地灌木生物量, 在群落调查时按照优 势物种的外貌将灌从分为3个类型: 散生型灌从、密 枝型灌从、匍匐型灌从。散生型灌从由分支明确、 枝干可数的灌木组成, 如山杏(Armeniaca sibirica) 灌丛; 密枝型灌从由分支不明确、枝干不可数的灌 木组成, 如荆条(Vitex negundo var. heterophylla)灌 从; 匍匐型灌从由从状或贴地生长的灌木组成, 如 小蓬(Nanophyton erinaceum)灌丛。采用不同方式调 查不同类型灌从的生物量。散生型灌从的生物量通 过标准株法获得, 在调查中记录样方内每株灌木的 基径和株高, 并在样方附近选择几株优势物种的标 准株, 测量其基径和株高, 分器官(根、茎、叶)收获、 称质量并取样, 样品称鲜质量后装入布袋带回实验 室。密枝型灌从的生物量通过收获法获得, 在每个 样方内选择有代表性的 $2 \mathrm{~m} \times 2 \mathrm{~m}$ 小样方, 对每个物 种分器官(根、茎、叶)收获、称质量并取样, 样品称 鲜质量后装入布袋带回实验室。匍匐型灌丛生物量 
也通过标准株法获得, 在调查中记录样方内每丛灌 木的冠幅长短轴长度和高度, 并在样方附近选择几 从优势物种的标准株, 测量其冠幅长短轴长度和高 度, 对每个物种分器官(根、茎、叶)收获、称量并取 样, 样品称鲜质量后装入布袋带回实验室。

草本层和调落物层生物量采用收获法获得, 在 每个样方选择 $1 \mathrm{~m} \times 1 \mathrm{~m}$ 的小样方, 依次收获草本地 上部分、调落物和草本地下部分, 称鲜质量并取样, 样品称鲜质量后装入布袋带回实验室。

为测定土壤元素含量, 在每个样方沿对角线用 土钻在0-10、10-20、20-30、30-50、50-70、70-100 $\mathrm{cm}$ 处采集土样并带回用于实验测定。

\section{2 生物量测定}

将野外采集的灌木、草本和调落物样品放入烘 箱, 在65 ${ }^{\circ} \mathrm{C}$ 下烘干至恒质量, 称其干质量。对于所 有样方的草本层和调落物, 以及密枝灌丛类型的灌 木层, 其干质量生物量由公式(1)算得:

生物量 $=$ (总鲜质量 $\times$ 样品干质量) $/$ 样品鲜质量 (1)

散生和匍匐灌从类型的灌木层生物量采用标准 株法计算。首先分种建立标准株地上生物量和测量 因子之间的相关生长关系(公式(2)、(3)):

$$
\begin{aligned}
& \log A G B_{A^{\prime}}=a+b \log \left(D^{2} \times H\right) \\
& \log A G B_{C^{\prime}}=a+b \log (d 1 \times d 2 \times H)
\end{aligned}
$$

其中, $A G B$ 为地上生物量, $A^{\prime}$ 和 $C^{\prime}$ 分别代表散生型和 匍匐型灌从标准株, $D$ 为基径, $d 1$ 和 $d 2$ 分别为冠幅长 短轴长度, $H$ 为株高, $a$ 和 $b$ 为参数。

利用标准株地上生物量和测量因子之间的相关 生长关系, 计算样方内所有植株的地上生物量, 求 和得到样方内灌木层地上总生物量。

茎和叶的生物量按照地上生物量和样品或标准 株的茎叶干质量比计算得到。灌木地下生物量通过 建立每个物种标准株的地上、地下生物量相关生长 关系计算(公式(4)):

$$
\log B G B_{i}=a+b \log \left(A G B_{i}\right)
$$

其中, $A G B_{i}$ 和 $B G B_{i}$ 分别为物种 $i$ 标准株的地上、地下 生物量, $a$ 和 $b$ 为参数。

利用标准株地上、地下生物量的相关生长关系, 计算样方内所有植株地下生物量, 求和得到样方内 灌木层地下总生物量。

\section{3 土壤元素含量测定}

野外采集的土壤样品经风干后带回实验室, 挑 选出砾石和粗根, 研磨过 $2 \mathrm{~mm}$ 篮, 并采用静电吸附
法去除细根。各层土壤样品的全碳和全氮含量用 C/N元素分析仪(2400II CHNS/O, PerkinElmer, Boston, USA)测定。土壤全磷含量采用酸溶-钼锑抗比色 法测定, 即用硫酸-高氯酸溶解土壤中的磷, 用钼锑 抗比色法测定。由于各层土壤的元素含量具有很强 的相关性, 本研究数据分析中仅使用0-10 $\mathrm{cm}$ 土壤 的元素含量。

\section{4 其他数据来源}

各样点年平均气温(MAT)和年降水量(AP)数据 来自于WorldClim数据库(http://www.worldclim.org/, 空间分辨率1 km × $1 \mathrm{~km})($ Hijmans et al., 2005)。

各灌丛群系的空间分布来自于 $1: 100$ 万中国植 被图(中国科学院中国植被图编辑委员会, 2007)。

\section{5 数据分析}

每种植被型的灌木层地上、地下平均生物量, 草本层地上、地下平均生物量, 以及平均调落物量 用调查样地相应生物量的平均值代表。每种植被类 型灌木层和草本层总生物量分别用其地上、地下平 均生物量加和计算, 地上和地下总生物量分别用对 应的灌木层和草本层平均生物量加和计算。

以各省的群系为基础, 计算同一省份同一群系 的所有样地平均生物量密度, 根据 1:100万中国植 被图(中国科学院中国植被图编辑委员会, 2007), 计 算中国北方灌从植被的生物量密度。将面积较小的 群系, 合并到同一省份物种组成相似的较大群系中。 由于亚热带灌从在研究区域中所占面积很小, 而且 在野外调查中没有包括, 分析中用同省份优势种亲 缘关系相近或者形态相似的落叶阔叶灌从样地的结 果进行估算, 因此并入了落叶阔叶灌丛进行分析。空 间数据的处理、计算和绘图在ArcGIS 10.3中完成。

调查样地的生物量与环境因子的关系采用一般 线性回归分析, 使用 R 软件完成(R Core Team, 2015)。

\section{2 结果}

\section{1 中国北方温带灌丛生态系统植被生物量密度}

中国北方灌丛植被平均生物量为 $12.5 \mathrm{t} \cdot \mathrm{hm}^{-2}$, 其中灌木层地上、地下平均生物量分别为 $(4.5 \pm 0.3)$ 和(5.4 \pm 0.4$) \mathrm{t} \cdot \mathrm{hm}^{-2}$, 草本层地上、地下平均生物量 分别为 $(0.8 \pm 0.0)$ 和 $(1.8 \pm 0.1) \mathrm{t} \cdot \mathrm{hm}^{-2}$ 。不同区域生物 量变异较大, 东部温带落叶灌丛生物量高于西部的 荒漠灌从，东部温带落叶灌从生物量一般高于 10 
$\mathrm{t} \cdot h \mathrm{~m}^{-2}$, 而西部荒漠区低于 $5.0 \mathrm{t} \cdot \mathrm{hm}^{-2}$ (图2)。其中温 带落叶灌从、亚高山落叶阔叶灌从、荒漠灌从3种植 被型平均生物量分别为14.4、28.8和 $5.0 \mathrm{t} \cdot \mathrm{hm}^{-2}$, 其中
平均地上生物量分别为6.0、13.0和 $2.5 \mathrm{t} \cdot \mathrm{hm}^{-2}$; 平均 生物量分别为 $8.4 、 15.8$ 和 $2.5 \mathrm{t} \cdot \mathrm{hm}^{-2}$ 。3种灌从类型 平均调落物量分别为 $(2.6 \pm 0.2) 、(2.2 \pm 0.5)$ 和(1.4

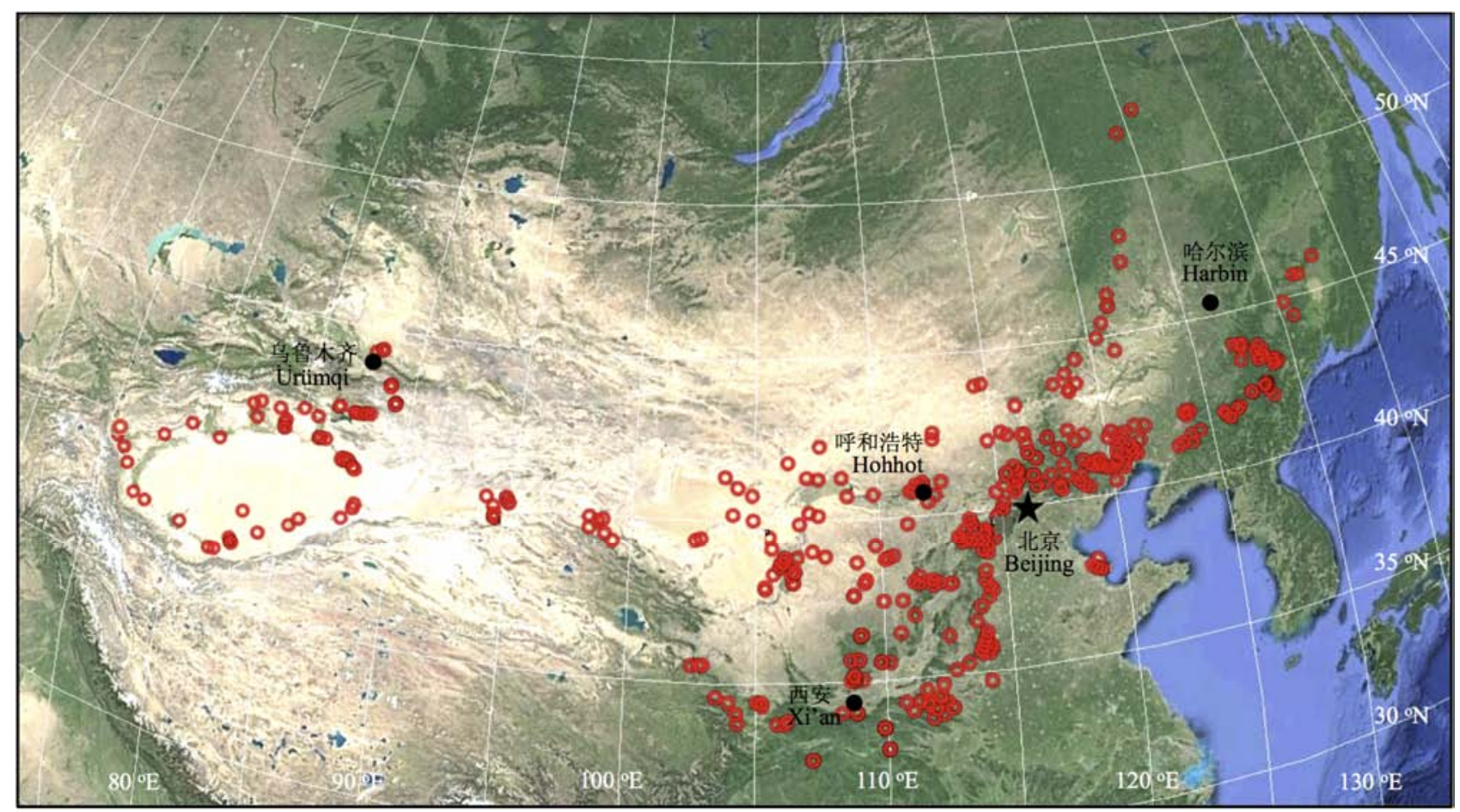

图1 样地分布图。

Fig. 1 Distribution of sampling sites.

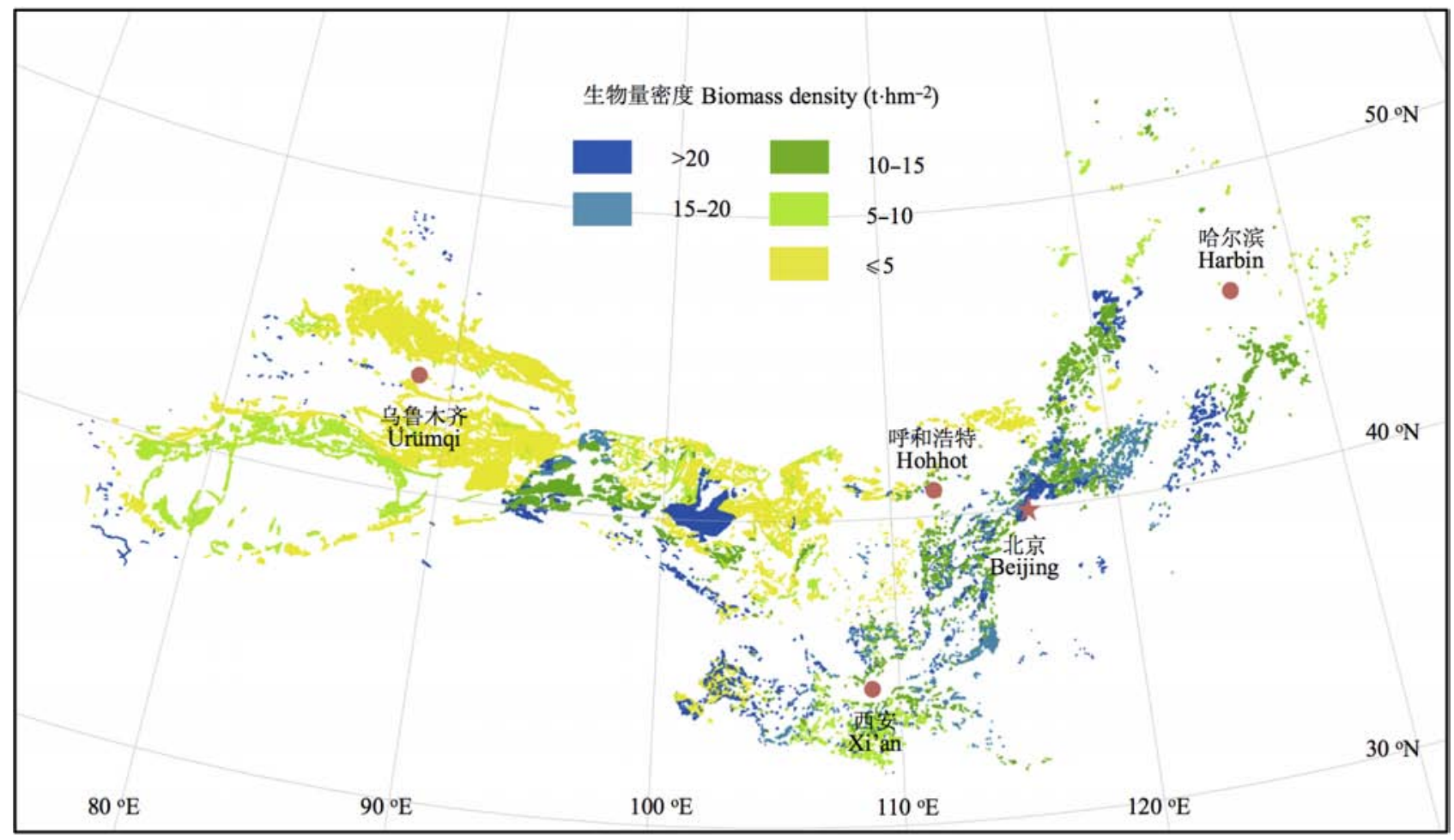

图2中国北方温带灌从植被总生物量空间分布格局。

Fig. 2 Spatial distribution of vegetation biomass in shrubland of the northern China. 
$\pm 0.2) \mathrm{t} \cdot \mathrm{hm}^{-2}($ 表1)。

灌木层和草本层植物地下生物量(图3B、3D、 $3 \mathrm{~F})$ 均高于地上生物量(图3A、3C、3E)。东部温带 落叶灌从灌木层植物地上 $\left(>5.2 \mathrm{vs} .<2.0 \mathrm{t} \cdot \mathrm{hm}^{-2}\right)$ 和地 下生物量 $\left(>6.5 \mathrm{vs} .<2.0 \mathrm{t} \cdot \mathrm{hm}^{-2}\right)$ 均略高于西部荒漠区 (图3A、3B)。草本层生物量在东西部差异较大, 草 本层地上和地下生物量都小于 $0.2 \mathrm{t} \cdot \mathrm{hm}^{-2}$ 的灌从大 部分出现在西部荒漠地区, 而草本层地上生物量超
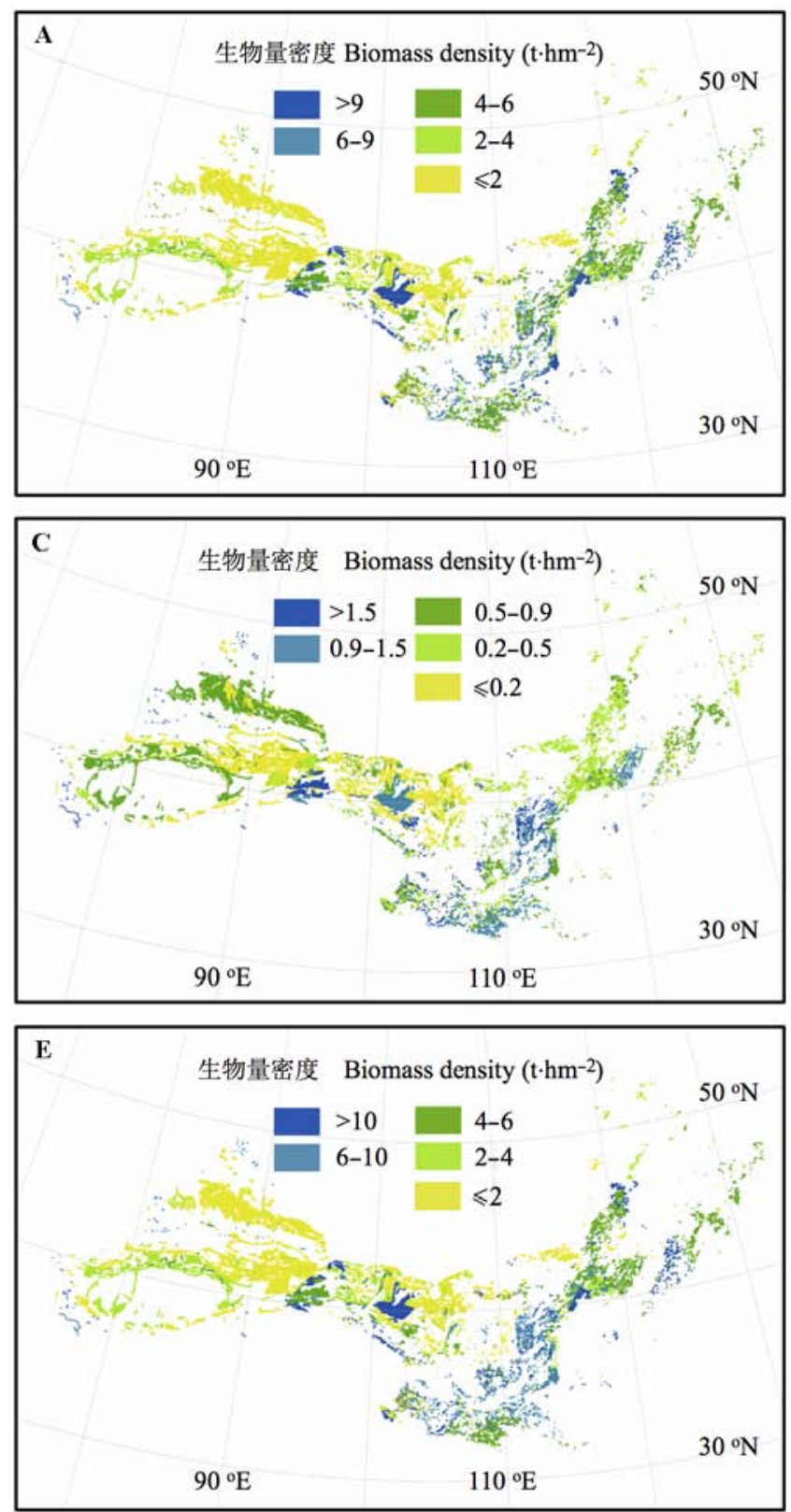

过 $0.9 \mathrm{t} \cdot \mathrm{hm}^{-2}$ 、地下生物量超过 $1.0 \mathrm{t} \cdot \mathrm{hm}^{-2}$ 的灌从大部 分出现在东部(图3C、3D)。草本层生物量远低于灌 木植物, 但草本层在空间分布上的差异加大了东西 部地上、地下总生物量的差异(图3E、3F)。

\section{2 中国北方灌丛地下-地上及叶-枝生物量分配格局}

由于亚高山落叶阔叶灌从调查样地数量少, 因 此只对温带落叶灌从和荒漠灌从灌木的地下-地上 生物量比及叶-枝生物量比进行了分析。温带落叶灌


图3 中国北方灌从不同组分生物量分布。 $\mathbf{A}$, 灌木层地上生物量。 $\mathbf{B}$, 灌木层地下生物量。 $\mathbf{C}$, 草本层地上生物量。 $\mathrm{D}$, 草 本层地下生物量。 E, 总地上生物量。F, 总地下生物量。

Fig. 3 Spatial distributions of above and belowground biomass in shrubland of the northern China. A, Aboveground biomass of shrub layer. B, Belowground biomass of shrub layer. C, Aboveground biomass of herb layer. D, Belowground biomass of herb layer. E, Total aboveground biomass. F, Total belowground biomass. 
表1 中国北方主要灌丛植被型的生物量密度

Table 1 Biomass density of major shrubland types of Northern China

\begin{tabular}{|c|c|c|c|c|}
\hline $\begin{array}{l}\text { 灌丛类型 } \\
\text { Shrubland type }\end{array}$ & $\begin{array}{l}\text { 温带落叶灌丛 } \\
\text { Temperate deciduous shrublands } \\
(\text { mean } \pm S E)\end{array}$ & $\begin{array}{l}\text { 亚高山落叶灌丛 } \\
\text { Alpine shrublands } \\
\text { (mean } \pm S E \text { ) }\end{array}$ & $\begin{array}{l}\text { 荒漠灌从 } \\
\text { Desert shrublands } \\
(\text { mean } \pm S E)\end{array}$ & $\begin{array}{l}\text { 所有 } \\
\text { Overall } \\
(\text { mean } \pm S E)\end{array}$ \\
\hline 样地数 No. of study site & 321 & 4 & 108 & 433 \\
\hline 生物量 Biomass $\left(\mathrm{t} \cdot \mathrm{hm}^{-2}\right)$ & 14.4 & 28.8 & 5.0 & 12.5 \\
\hline 地上生物量 Aboveground biomass & 6.0 & 13.0 & 2.5 & 5.3 \\
\hline 灌木层 Shrub layer & $5.2 \pm 0.3$ & $12.2 \pm 4.3$ & $2.0 \pm 0.3$ & $4.5 \pm 0.3$ \\
\hline 草本层 Herb layer & $0.8 \pm 0.0$ & $0.8 \pm 0.2$ & $0.4 \pm 0.1$ & $0.8 \pm 0.0$ \\
\hline 地下生物量 Belowground biomass & 8.4 & 15.8 & 2.5 & 7.2 \\
\hline 灌木层 Shrub layer & $6.5 \pm 0.4$ & $13.2 \pm 6.4$ & $2.0 \pm 0.5$ & $5.4 \pm 0.4$ \\
\hline 草本层 Herb layer & $1.9 \pm 0.1$ & $2.6 \pm 0.3$ & $0.5 \pm 0.1$ & $1.8 \pm 0.1$ \\
\hline 凋落物量 Litterfall (t·hm $\left.{ }^{-2}\right)$ & $2.6 \pm 0.2$ & $2.2 \pm 0.5$ & $1.4 \pm 0.2$ & $2.5 \pm 0.2$ \\
\hline
\end{tabular}

SE, 标准误差。

$S E$, standard error.
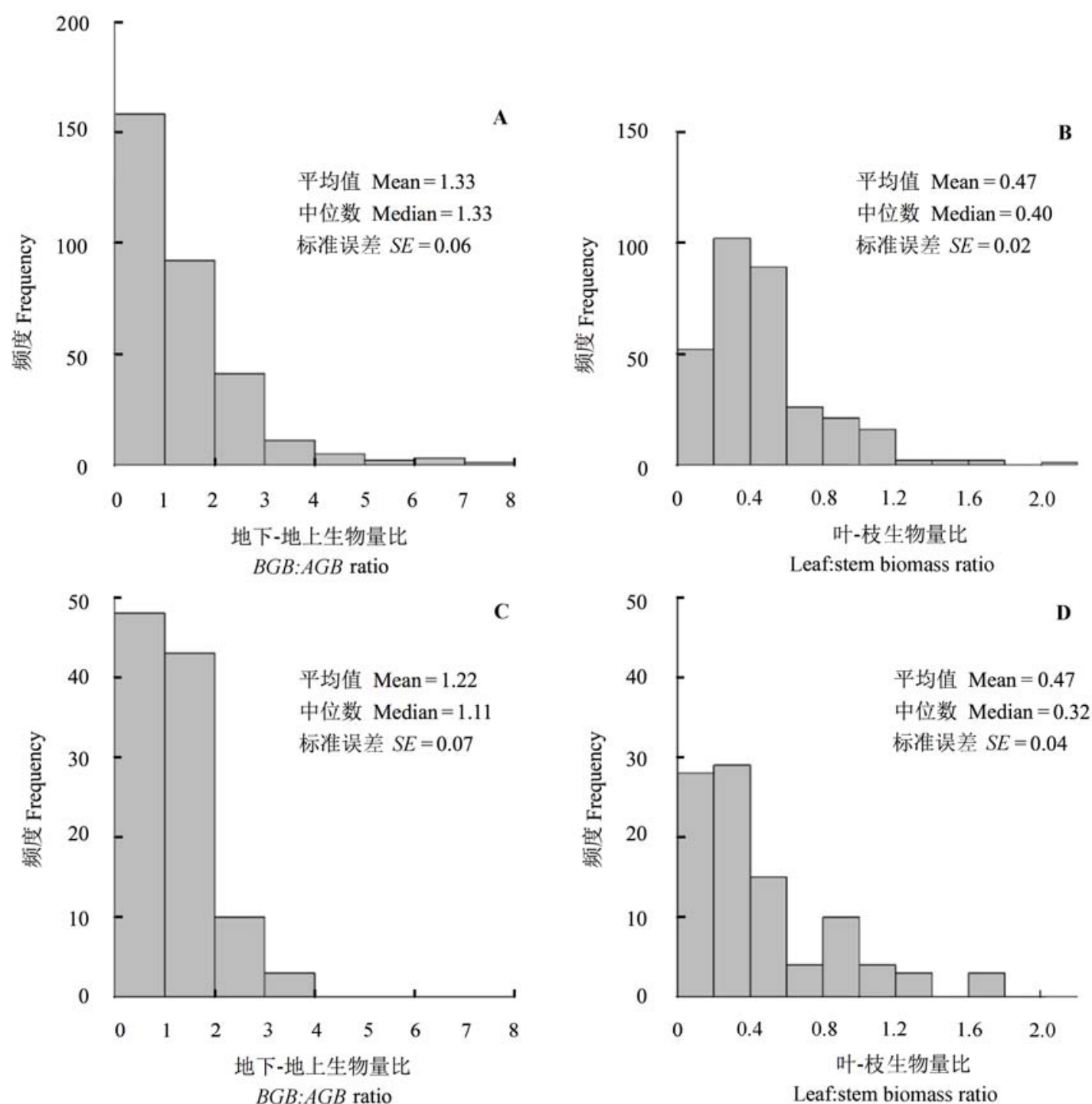

图4 中国北方温带落叶灌从和荒漠灌从灌木地下-地上生物量比和叶-枝生物量比频度分布, A, 温带落叶灌丛地下-地上生 物量比。 B, 温带落叶灌从叶-枝生物量比。C, 荒漠灌丛地下-地上生物量比。D, 荒漠灌丛叶-枝生物量比。

Fig. 4 Frequency distributions of belowground:aboveground biomass ratio (BGB:AGB) and leaf:stem biomass ratio of shrubs in the temperate deciduous shrubland and dessert shrubland of the northern China. A, Belowground:aboveground biomass ratio in the temperate deciduous shrubland. B, Leaf:stem biomass ratio in the temperate deciduous shrubland. C, Belowground: aboveground biomass ratio in the dessert shrubland. D, Leaf:stem biomass ratio in the dessert shrubland. 

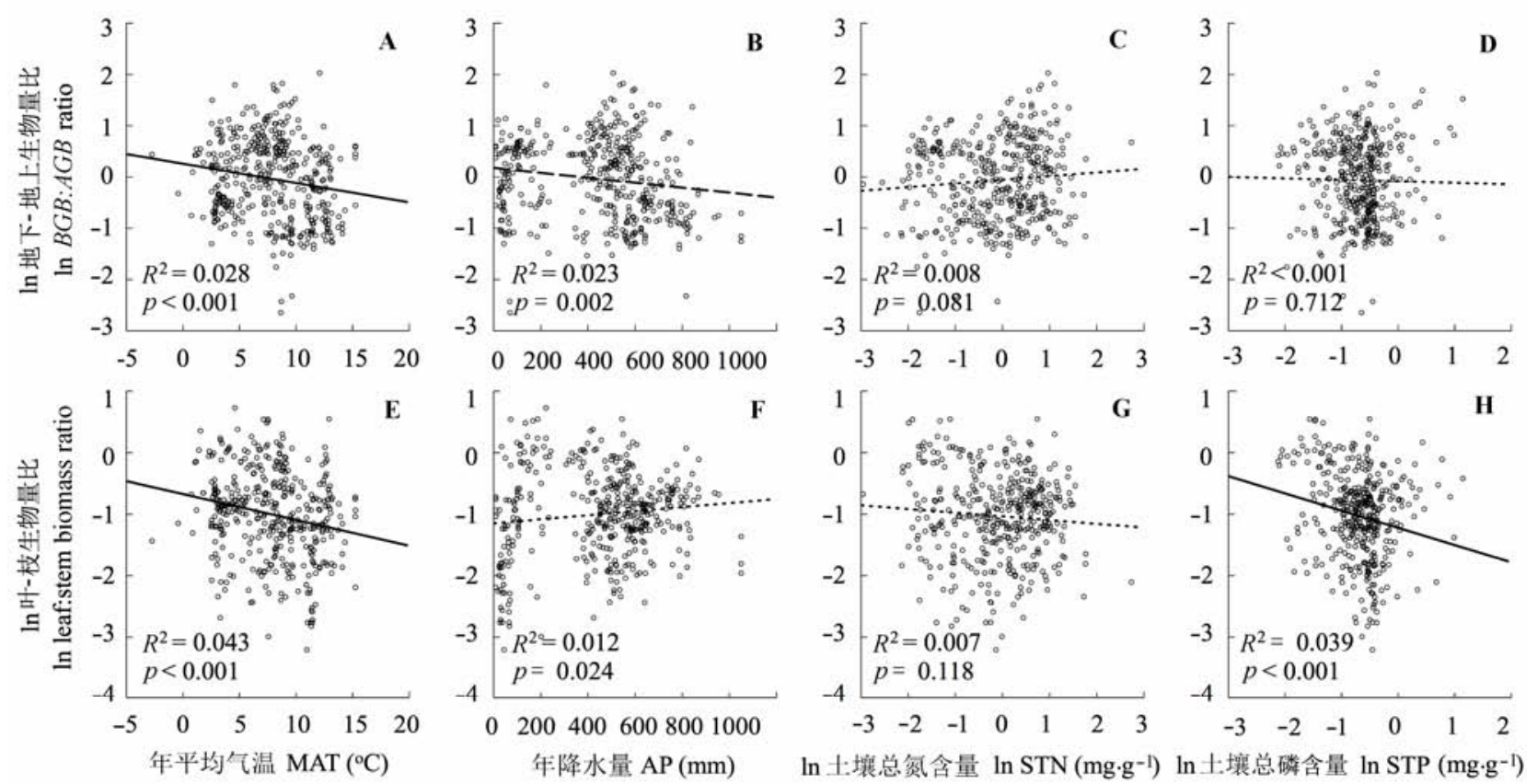

图5 中国北方灌丛地下-地上生物量比(A-D)和叶-枝生物量比(E-H)与环境的关系。点线: $p>0.01$; 短划线: $0.001<p<$ 0.01 ; 实线: $p<0.001$ 。

Fig. 5 Distribution of belowground:aboveground biomass ratio (A-D) and leaf:stem biomass ratio (E-H) in shrubland of the northern China in relation to environmental variables. Fitted lines show significant relationships (dotted line: $p>0.01$; dashed line: $0.001<p<0.01$; solid line: $p<0.001$ ). AGB, aboveground biomass; $B G B$, belowground biomass. MAT, mean annual temperature; AP, annual precipitation; STN, soil total nitrogen concentration; STP, soil total phosphorus concentration.

从灌木的地下-地上和叶-枝生物量比变异比荒漠灌 从丛。温带落叶灌从灌木的平均地下-地上生物量比 为 $(1.33 \pm 0.06)$, 平均叶-枝生物量比为 $(0.47 \pm 0.02)$, 荒漠灌丛的平均地下-地上生物量比为(1.22 \pm 0.07$)$, 平均叶-枝生物量比为 $(0.47 \pm 0.04)$ (图4)。

中国北方灌从灌木地上-地下生物量比随年平 均气温、年降水量增加而显著减少(年平均气温: $p<$ 0.001 , 年降水量: $p=0.002$ ), 但随土壤氮和磷含量 的变化无显著变化规律 $(p>0.05)$ 。灌木层叶-枝生物 量比随年平均气温和土壤磷增加而显著降低 $(p<$ $0.001)$, 但随年降水的增加趋势较弱 $(p=0.024)$, 随 土壤磷无显著的变化趋势 $(p>0.05)$ (图5)。

\section{3 讨论}

研究区域内, 灌丛植被生物量变异较大, 这种 差异在不同层次均有所体现, 但其地上-地下生物 量分配较为一致。灌木地下-地上生物量比受土壤营 养的影响不显著 $(p>0.05)$, 受水分影响的显著性也 较低 $(p=0.002)$ 。这一结果与Yang等(2009)对青藏高 原高寒草地地上-地下生物量比的研究结果一致。根 据平衡生长假说(Bloom et al., 1985; Chapin et al., 1987), 植物会权衡生物量在各个器官间的分配来
适应不同的水分、光照或养分条件, 使其生长速率 达到最大值。比如, 在水分、养分缺乏的条件下, 植 物的生物量将更多分配到地下部分。本研究对地下地上生物量比的研究结果不能支持这一假说。 McCarthy和Enquist (2007)利用全球森林的生物量 数据对平衡生长假说进行了验证, 认为该假说只适 用于种内生物量分配, 而不适用于种间生物量分配 的比较。在种间, 不同植物可能通过其他方式来适 应环境, 例如改变各器官间元素分配(Yang et al., 2014)。灌木叶-枝生物量比随年平均气温升高而显 著降低, 却随年降水量增加而增加, 可能是由于随 着温度增加蒸腾作用增强, 植物为了减少水分的丧 失, 通过调整生长分配模式来减少叶生物量来适应 干旱(Marke- teijn \& Poorter, 2009)。另外, 还有很多 旱生灌木的叶片退化, 利用绿色的同化枝或叶轴进 行光合作用。因此, 随着降水的减少, 植物叶-枝生 物量比降低。

通过对中国北方温带灌从分布区的大范围野外 调查, 本文计算了中国北方灌丛植物的生物量及植 物各器官生物量的分配比例, 并结合植被分布, 研 究了灌从生态系统生物量密度分布格局, 为估算灌 从生态系统的碳储量奠定了基础。结果表明, 中国 
北方温带灌从平均生物量为 $12.5 \mathrm{t} \cdot \mathrm{hm}^{-2}$, 其中灌木 层地上、地下平均生物量分别为 4.5 和 $5.4 \mathrm{t} \cdot \mathrm{hm}^{-2}$, 草 本层地上、地下平均生物量分别为 0.8 和 $1.8 \mathrm{t} \cdot \mathrm{hm}^{-2}$, 调落物量为 $2.5 \mathrm{t} \cdot \mathrm{hm}^{-2}$ 。不同类型中, 温带落叶灌从、 亚高山落叶阔叶灌从、荒漠灌丛平均生物量分别为 14.4、28.8和5.0 $\mathrm{t} \cdot \mathrm{hm}^{-2}$ 。东西部生物量分布差异较 大。环境对生物量在各器官的分配有一定影响, 灌 木的地下-地上生物量比不随水分和土壤养分变化 而变化, 而叶-枝生物量比受水分影响, 在干旱区域 叶-枝生物量比较低。本研究的估算中也存在一定的 不确定性, 主要原因是一些分布面积较小的灌丛类 型的生物量采用优势种亲缘关系相近或者形态相似 的样地平均值代替, 一些数量较少或采集困难的物 种的相关生长方程利用近缘物种的标准株建立, 这 可能会造成对某些物种和灌丛类型生物量估算的误 差。随着调查数据的补充, 此类误差将会减小。

基金项目中国科学院战略先导性科技专项 (XDA05050301和XDA05050700) 和科技部科技基 础性工作专项(2011FY110300)。

\section{参考文献}

Bai Y, Wu J, Xing Q, Pan Q, Huang J, Yang D, Han X (2008). Primary production and rain use efficiency across a precipitation gradient on the Mongolia plateau. Ecology, 89, 2140-2153.

Bloom AJ, Chapin FS, Mooney HA (1985). Resource limitation in plants-An economic analogy. Annual Review of Ecology and Systematics, 16, 363-392.

Chapin FS, Bloom AJ, Field CB, Waring RH (1987). Plant responses to multiple environmental factors. Bioscience, 37, 49-57.

Chen XL, Ma QY, Kang FF, Cao WQ, Zhang GH, Chen ZW (2002). Studies on the biomass and productivity of typical shrubs in Taiyue Mountain, Shanxi Province. Forest Research, 15, 304-309. (in Chinese with English abstract) [陈遐林, 马钦彦, 康峰峰, 曹文强, 张国华, 陈宗伟 (2002). 山西太岳山典型灌木林生物量及生产力研究. 林业科学研究, 15, 304-309.]

Gao Q, Yang XC, Yin CY, Liu Q (2014). Estimation of biomass allocation and carbon density in alpine dwarf shrubs in Garzê Zangzu Autonomous Prefecture of Sichuan Province, China. Chinese Journal of Plant Ecology, 38, 355-365. (in Chinese with English abstract) [高巧, 阳小 成, 尹春英, 刘庆 (2014). 四川省甘孜藏族自治州高寒 矮灌丛生物量分配及其碳密度的估算. 植物生态学报, 38, 355-365.]

He JS, Wang QB, Hu D (1997). Studies on the biomass of typical shrubland and their regeneration capacity after cutting. Acta Phytoecologica Sinica, 21, 512-520. (in Chinese with English abstract) [贺金生, 王其兵, 胡东 (1997). 长江三峡地区典型灌丛的生物量及其再生能力. 植物 生态学报, 21, 512-520.]

Hijmans RJ, Cameron SE, Parra JL, Jones PG, Jarvis A (2005). Very high resolution interpolated climate surfaces for global land areas. International Journal of Climatology, 25, 1965-1978.

Hu HF, Wang ZH, Liu GH, Fu BJ (2006). Vegetation carbon storage of major shrublands in China. Journal of Plant Ecology (Chinese Version), 30, 539-544. (in Chinese with English abstract) [胡会峰, 王志恒, 刘国华, 傅伯杰 (2006). 中国主要灌丛植被碳储量. 植物生态学报, 30, 539-544.]

Jiang FQ, Lu FY (1982). The model of estimating above-ground biomass of Caragana microphylla brush. Acta Ecologica Sinica, 2, 103-110. (in Chinese with English abstract) [姜凤岐, 卢凤勇 (1982). 小叶锦鸡儿灌丛 地上生物量的预测模式. 生态学报, 2, 103-110.]

Lei L, Liu XD, Wang SL, Li Y, Zhang XL (2011). Assignment rule of alpine shrubs biomass and its relationships to environmental factors in Qilian Mountains. Ecology and Environmental Sciences, 20, 1602-1607. (in Chinese with English abstract) [雷蕾, 刘贤德, 王顺利, 李毅, 张学龙 (2011). 祁连山高山灌丛生物量分配规律及其与环境因 子的关系. 生态环境学报, 20, 1602-1607.]

Liu GH, Zhang JY, Zhang YX, Zhou JY, Guan WB, Ma KM, $\mathrm{Fu} B J$ (2003a). Distribution regulation of aboveground biomass of three main shrub types in the dry valley of Minjiang River. Journal of Mountain Science, 21, 24-32. (in Chinese with English abstract) [刘国华, 张洁瑜, 张育 新, 周建云, 关文涁, 马克明, 傅伯杰 (2003a). 岷江干 旱河谷三种主要灌丛地上生物量的分布规律. 山地学 报, 21, 24-32.]

Liu GH, Ma KM, Fu BJ, Guan WB, Kang YX, Zhou JY, Liu SL (2003b). Aboveground biomass of main shrubs in dry valley of Minjiang River. Acta Ecologica Sinica, 23, 1757-1764. (in Chinese with English abstract) [刘国华, 马克明, 傅伯杰, 关文涁, 康永祥, 周建云, 刘世梁 (2003b). 岷江干旱河谷主要灌从类型地上生物量研究. 生态学报, 23, 1757-1764.]

Luo TX, Li WH, Luo J, Wang QJ (1999). A comparative study on biological production of major vegetation types on the Tibetan Plateau. Acta Ecologica Sinica, 19, 823-831. (in Chinese with English abstract) [罗天祥, 李文华, 罗辑, 王启基 (1999). 青藏高原主要植被类型生物生产量的 比较研究. 生态学报, 19, 823-831.]

Markesteijn L, Poorter L (2009). Seedling root morphology and biomass allocation of 62 tropical tree species in relation to 
drought- and shade-tolerance. Journal of Ecology, 97, 311-325.

McCarthy MC, Enquist BJ (2007). Consistency between an allometric approach and optimal partitioning theory in global patterns of plant biomass allocation. Functional Ecology, 21, 713-720.

Poorter H, Niklas KJ, Reich PB, Oleksyn J, Poot P, Mommer L (2012). Biomass allocation to leaves, stems and roots: Meta-analyses of interspecific variation and environmental control. New Phytologist, 193, 30-50.

R Core Team (2015). R: A language and environment for statistical computing. Vienna, Austria. https://www.Rproject.org/. Cited: 2015-12-10.

Subbarao GV, Johansen C, Slinkard AE, Nageswara Rao RC, Saxena NP, Chauhan YS, Lawn RJ (1995). Strategies for improving drought resistance in grain legumes. Critical Reviews in Plant Sciences, 14, 469-523.

The Editorial Committee of Vegetation Map of China, Chinese Academy of Sciences (2007). Vegetation Map of the People's Republic of China 1:1000 000. Geological Publishing House, Beijing. (in Chinese) [中国科学院中国 植被图编辑委员会 (2007). 中华人民共和国植被图 1:1 000 000. 地质出版社, 北京.]

Turner BL, Haygarth PM (2001). Biogeochemistry: Phosphorus solubilization in rewetted soils. Nature, 411, 258.

Wang W, Peng SS, Fang JY (2008). Biomass distribution of natural grasslands and it response to climate change in north China. Arid Zone Research, 25, 90-97. (in Chinese with English abstract) [王娓, 彭书时, 方精云 (2008).
中国北方天然草地的生物量分配及其对气候的响应. 干旱区研究, 25, 90-97.]

Wang YJ, Huang CD, Zhang J, Yang WQ, Wang XS (2010). Species diversity biomass and their relationship of shrubberies in an arid valley of the Minjiang River. Arid Zone Research, 27, 567-572. (in Chinese with English abstract) [王勇军, 黄从德, 张健, 杨万勤, 王宪帅 (2010). 怅江 干旱河谷灌丛物种多样性, 生物量及其关系. 干旱区研 究, 27, 567-572.]

Yang Y, Fang J, Ji C, Han W (2009). Above- and belowground biomass allocation in Tibetan grasslands. Journal of Vegetation Science, 20, 177-184.

Yang Y, Fang J, Ma W, Guo D, Mohammat A (2010). Largescale pattern of biomass partitioning across China's grassland. Global Ecology \& Biogeography, 19, 268-277.

Yang X, Tang Z, Ji C, Liu H, Ma W, Mohhamot A, Shi Z, Sun W, Wang T, Wang X (2014). Scaling of nitrogen and phosphorus across plant organs in shrubland biomes across Northern China. Scientific Reports, 4, 5448.

Zhong ZB, Yang LC, Liu HC, Song WZ, Li F, Zhou GY (2014). The main shrubs aboveground biomass and effect factors in Yushu, Qinghai, China. Mountain Research, 32, 678-684. (in Chinese with English abstract) [钟泽兵, 杨 路存, 刘何春, 宋文珠, 李璠, 周国英 (2014). 青海玉 树地区主要灌从类型地上生物量及其影响因素. 山地 学报, 32, 678-684.]

责任编委: 谢宗强 责任编辑: 王 蒇

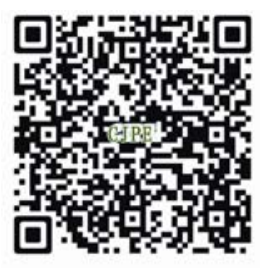

植物生态学报官网

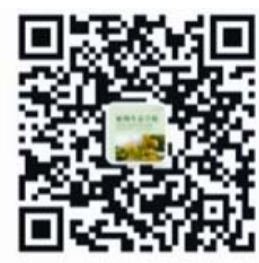

微信订阅号

期刊及学科

相关信息发布

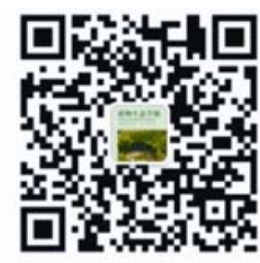

微信服务号

稿件状态查询

全文检索浏览 